\title{
The Moderating Effects of Value Similarity and Company Philosophy on the Climate-Commitment Relationship
}

\author{
Cathy A. Enz, Ph.D. \\ Indiana University
}

\begin{abstract}
The present study examines the moderating effects of two components of culture (value similarity and company philosophy) on the relationship between organizational climate and commitment. Moderator regression analyses reveal that value similarity has a direct effect on levels of commitment but does not moderate the climate-commitment relationship. In contrast, company philosophy is found to affect commitment directly but also to moderate the relationship between the reward and consideration dimensions of climate and organizational commitment. The results provide support for a culture-based explanation of commitment and offer some insights into the linkage between climate and organizational culture.
\end{abstract}

An organization's culture is thought to be a critical and commonly ignored factor in explaining organizational behaviors and attitudes. Until recently, mostly anecdotal support was presented as evidence for the impact of culture on organizational identification and loyalty. A tendency existed to discount the importance of culture by citing the conceptual and methodological flaws of books such as In Search of Excellence, by Peters and Waterman (1983), or Company Cultures, by Deal and Kennedy (1983). Some scoffed at the concept for being too vague, general, and impossible to measure.

In recent years, however, more academics have come to realize that the culture of an organization plays as critical a role in the attitudes of employees as the formal structures and managerial policies. Organizational researchers have begun to argue explicitly that culture affects employee commitment and operating performance (Sathe 1985; Saffold 1988).

The expanding empirical research on organizational culture provides a strong case for its impact on the firm. Denison (1983) found in a study of 34 corporations that the nature of the organizational culture influenced performance. Specifically, he concluded that the ideals or vision of organization members have a greater impact on performance than actual behaviors. Posner, Kouzes, and Schmidt (1985) conducted a national survey of managers in which they found shared values to be related to organizational commitment, 
personal success, self-confidence, ethical behavior, and organizational goals. They stressed the fit between personal and organizational goals. Other studies, focusing on the values component of culture, have shown that organizational value similarity explains subunit power, strategic decision making, and operating unit performance (Enz 1988, in press; Enz and Schwenk 1989).

An entire volume of Administrative Science Quarterly (1983) was devoted to the study of organizational cultures and numerous books have emerged since the early 1980s. Taken together, existing studies, anecdotal writings, and recent attempts at theory development provide evidence to suggest that organizational culture does play an important role in the functioning and managing of businesses.

The purpose of this study is to explore the moderating effects of two components, value similarity and company philosophy, on the linkage between organizational climate and employee commitment. Before discussing in detail the linkages between culture, climate, and commitment it is necessary to define the cultural components and clarify terminology.

\section{VALUE SIMILARITY AND COMPANY PHILOSOPHY DEFINED}

Shared values and company philosophies are two of the most central facets of an organization's culture according to recent reviews of the culture literature (Wiener 1988; Ott 1989). Wiener (1988) notes that shared values consistently emerge in the diverse cultural literature as a core element. Organizational culture is conceived as a set of common understandings or meanings which include shared beliefs, norms, values, and guiding principles or philosophies (Pettigrew 1979; Louis 1983).

Enz $(1986,27)$ states that organizational values are "Beliefs that speak to the actions and goals (ends) organizations 'ought to' or 'should' identify in the running of the enterprise." When a number of key organizational values are shared by members in the organization, then value similarity is said to exist. In the present study value similarity is defined as the degree of perceived similarity on organizationally relevant values (e.g., efficient use of resources and product quality).

The second component of organizational culture is the company philosophy, defined here as a set of beliefs that serves as a doctrine or system of guiding principles within the organization. A company philosophy is defined by decision makers in the organization, is formal, articulated, and a reasoned set of guiding principles designed to guide conduct within a particular firm. The present study explores the degree to which a firm is regarded as possessing a 
distinct and well- known overreaching company philosophy.

In summary, value similarity and company philosophy were selected for inclusion in this study because of their centrality to the culture concept and their use in previous empirical work (Enz 1988; O’Reilly 1983).

\section{ORGANIZATIONAL CLIMATE AND CULTURE}

The recent popularity of organizational culture, specifically the role of shared values and company philosophy, has led some to question the conceptual distinctiveness of the climate and culture constructs. Confusion between these two constructs can be attributed in part to the casual and overlapping use of the terms by many (Schneider 1985). Some researchers use the term culture when they are measuring dimensions of climate (e.g., O'Toole 1979). Others conceptualize climate in a fashion similar to the definition of culture but use an existing operationalization of climate.

Trice, Beyer, and Morand (1985) argue that organizational culture and climate are distinct, and an understanding of the differences is essential if we are to benefit from what these constructs can offer. Burke (1985) reinforces this claim by noting that distinctions can be made between climate and culture. He notes that culture addresses values, whereas climate stresses perceptions of the organizational context. Culture researchers want to understand the value system and how values are transmitted, according to Schneider (1985). The climate researchers, in contrast, are concerned with the dimensions of the particular organizational environment. Dimensions such as the degree of decision-making autonomy, supervisory consideration, and rewards for effort are commonly studied in the area of climate. Climate is an indicator of an organization's current atmosphere and describes what happens around here (Schneider and Rentsch 1989). Rousseau (1988) notes that climate reflects how one feels about the current setting, while culture stresses how one "should" behave. Culture captures the values that underlie climate; thus they are complementary as well as distinct.

Climate and culture may work in concert to explain organizational outcomes such as commitment. For example, when values are shared and company philosophies are known, the climate may be altered. The degree of value similarity and knowledge regarding the company philosophy may indeed moderate the relationship between climate and organizational commitment. Hence, the interaction between climate and culture is of particular interest in this study. 
It has been suggested that culture and climate are distinct but intertwined. Unfortunately little if any empirical research to date has attempted to distinguish operationally between culture and climate or determine the effects of one on the other. Both culture and climate researchers can be criticized for ignoring the complementary works of the other group and for neglecting to examine how climate and culture work together in explaining organizational attitudes and behaviors. Culture may inform and modify the effects of the organizational setting (climate) on levels of commitment; thus the present study will provide a first attempt at exploring this possibility.

\section{ORGANIZATIONAL COMMITMENT}

Organizational commitment is a factor frequently cited as central to explanations of desired work behavior. Commitment is regarded as a willingness of employees to go beyond compliance to expressions of loyalty (Mowday, Steers, and Porter 1979). The extensive literature on commitment has examined numerous antecedents and outcomes (Steers 1977; Angle and Perry 1981; Koch and Steers 1978; Morris and Sherman 1981; Bateman and Strasser 1984), although little has yet been done regarding the role of culture in explaining commitment.

The present study seeks to explore the linkages between climate, culture, and commitment. While little empirical work has explored the relationships among these variables, a host of writers have suggested that the linkages exist and are important.

\section{HYPOTHESES}

The first objective of the present research is to examine the relationships among organizational commitment, dimensions of organizational climate, and the two components of organizational culture. Recently Schneider and Rentsch (1989) noted that both climate and culture determine the degree of identification. Hence, it is expected that the organizational climate, degree of value similarity, and strength of the company philosophy will be positively related to commitment as the following hypothesis indicates.

HI: Value sharing, company philosophy, and organizational climate are positively associated with commitment.

In support of this hypothesis, Sathe (1983) has suggested but not empirically demonstrated that organizational culture determines the levels of loyalty 
and identification expressed by commitment. Posner et al. (1985) report a positive relationship between personal and organizational value fits and degree of commitment. Thus it seems plausible to argue that the greater the value sharing and the stronger the company philosophy, the higher the level of organizational commitment.

Previous studies have also found support for the relationship between some dimensions of organizational climate and commitment. Reward policies (Lee 1971), goals (Hall and Schneider 1973), and participation (Welsch and LaVan 1981) are organizational climate factors which have all been found to be related to commitment. Given these preliminary findings regarding climate, it seems possible to suggest that various components of an organization's current climate will also influence commitment.

The second purpose of this study is to test for the moderating effects of value similarity and company philosophy on the relationship between climate and commitment. It is expected that the relationship between climate and commitment is not constant but is likely to vary with changes in cultural factors as the second hypothesis notes.

$\mathrm{H} 2$ : Value sharing and company philosophy will moderate the relationship between the dimensions of climate and organizational commitment.

The reason for examining the moderating effects of cultural variables on the climate-commitment relationship is to ascertain whether the linkage between climate and commitment is contingent on the form of the cultural components (Arnold 1982). More specifically this hypothesis explores the question: Does the relationship between the current organizational climate and commitment vary according to the degree of value sharing and the strength of the company philosophy?

\section{METHODS}

\section{Sample}

This study was conducted in a midwestem food processing division of a large, privately held organization. The parent company is a family owned multinational confectionery organization. Data were collected in two stages. In the first stage 36 divisional personnel were interviewed using a structured, open- ended interview format. Interviewees were randomly selected but represented all departments and hierarchical levels within the division. The second stage involved on-site administration and collection of a structured 
questionnaire. A total of 162 usable surveys were collected from the divisional personnel for a response rate of $69 \%$. Participation was voluntary and employees from all factory shifts and the office were involved in both stages.

Of these surveyed, $82 \%$ were male, and $76 \%$ were white. Over $65 \%$ of the employees had worked for the company for over ten years. The average employee was 35 years old and had attended but had not graduated from college. Most employees grew up in lower-middle (25\%) to middle class $(46 \%)$ households in either rural areas (41\%) or large cities (26\%).

\section{Measures}

Organizational commitment was measured using a 15-item scale developed by Porter et al. (1974). This measure was developed to capture an individual's identification with and involvement in a particular organization. Mowday, Steers, and Porter (1979) report the psychometric properties of this scale based on eight separate samples. An internal consistency reliability (coefficient alpha) of .81 was found in this study.

Climate was measured using the four dimensions of climate (autonomy, consideration, rewards, and structure) identified by Campbell, Dunnette, Lawler, and Weick (1970). These scales were first developed by Dieterly and Schneider (1974). In keeping with these earlier operationalizations, autonomy is the freedom of an employee to be his own boss and reserve considerable decisionmaking power for himself. Consideration is the support and warmth received from a superior. The reward dimension captures the degree to which the organization rewards effort and is profit oriented. Structure is the degree to which objectives or methods for doing the job are established and communicated to employees.

The reliability and validity of these scales have been psychometrically tested in previous studies. In this study the Cronbach alphas were .64 for autonomy, .80 for consideration, .30 for structure, and .72 for rewards. Given the extremely small internal consistency for the structure dimension caution should be exercised in interpreting the findings for this variable. Since the reliability coefficient for the structural dimension is low, the findings obtained using this instrument will not be stressed or discussed in detail. While confidence does exist for the viability of the climate instruments given their frequent use in previous studies, greater attention will be placed in the present study on the three dimensions which yielded high reliability coefficients.

Organizational Culture captures the shared values and beliefs that employees collectively share. To measure culture, we examined two specific components: value similarity and company philosophy. 
Value similarity was measured with a 5-item scale designed to capture the degree to which employees perceived themselves as similar to management on organizationally relevant values. To arrive at the specific values, interviews were conducted with a random sample of division personnel. Based on the most frequently cited organizational values identified in the interviews and a manual of the company's philosophy, five specific values were selected. Respondents were asked to indicate how similar they were to top management on these values using a 7-point scale ranging from "very similar" to "very dissimilar." An internal consistency reliability (Cronbach alpha) of .83 was found for this scale.

Listed below are the five values and a description of each value that was provided to the respondents. All employees were familiar with the general value terms used and could consistently and easily provide the definitions offered below. Hence, these value statements were grounded in the organization studied.

1. Freedom-We need freedom to shape our future; we need profit to remain free.

2. Efficiency-We use resources to the full, waste nothing, and do only what we can do best.

3. Mutuality-A mutual benefit is a shared benefit; a shared benefit will endure.

4. Responsibility-As individuals, we demand total responsibility from ourselves; as employees, we support the responsibilities of others.

5. Quality-The customer is our boss, quality is our work, and value for money is our goal.

Company philosophy was measured using a 6-item scale. The work of O'Reilly (1983) was used as a basis for the development of this scale. The instrument captures the degree to which the company had a distinct and wellknown philosophy. A Cronbach alpha of .81 was found for this scale in the present study.

In order to determine the conceptual distinctiveness of the two cultural measures, we conducted a principle components factor analysis. As the varimax rotated factor loadings in Table 1 suggest, the two measures of culture are clearly distinct and indicate two underlying factors. Factor I reflects the degree of value similarity between employees and the company. Factor II captures the degree to which a distinct and respected company philosophy 
exists. The two factors accounted for $56.50 \%$ of the total variance in the sample.

\section{ANALYSIS AND RESULTS}

Means, standard deviations, and the intercorrelation matrix of all the variables is given in Table 2 . The climate dimensions of autonomy, considera-

TABLE 1

VARIMAX ROTATED FACTOR LOADING

FOR THE CULTURAL MEAURES

\begin{tabular}{|c|c|c|}
\hline \multirow[b]{3}{*}{ Items } & \multicolumn{2}{|c|}{ Factor Loadings } \\
\hline & Factor $\mathbf{I}$. & Factor II. \\
\hline & $\begin{array}{c}\text { Value } \\
\text { Similarity }\end{array}$ & $\begin{array}{l}\text { Company } \\
\text { Philosophy }\end{array}$ \\
\hline \multicolumn{3}{|l|}{ Value Similarity } \\
\hline 1. Similarity on freedom to shape the future & 627 & .297 \\
\hline 2. Similarity on efficient use of resources & .723 & .080 \\
\hline 3. Similarity on mutality of benefits & .779 & .242 \\
\hline 4. Similarity on responsibility & .783 & .243 \\
\hline 5. Similarity on product quality & .840 & .009 \\
\hline \multicolumn{3}{|l|}{ Company Philosophy } \\
\hline 1. Vision of company known and respected & .267 & .542 \\
\hline 2. Company philosophy means something & .283 & .710 \\
\hline 3. I know the company philosophy & .041 & .800 \\
\hline \multicolumn{3}{|l|}{ 4. You could work here for years and never } \\
\hline know the company philosophy (Reverse) & .071 & .698 \\
\hline 5. Company's goals mean something & .174 & .746 \\
\hline 6. Company has a distinct philosophy & .140 & .691 \\
\hline Eigenvalues & 4.40 & 1.82 \\
\hline Percent of Variance Explained & 40.00 & 16.60 \\
\hline Cumulative Variance Explained & 40.00 & 56.50 \\
\hline
\end{tabular}

tion, and rewards were all significantly correlated with commitment, and value similarity and company philosophy were also positively associated with commitment. The largest correlation exists between company philosophy and commitment. Value similarity and company philosophy were significantly 
correlated with each other $(r=.40)$, but they were sufficiently independent to support the contention that they represent separate components of culture. These results provide support the the first hypothesis, indicating that the two measures of culture and three of the four measures of climate are significantly associated with commitment.

TABLE 2

MEANS, STANDARD DEVIATIONS, AND INTERCORRELATIONS AMONG ALL THE VARIABLES ${ }^{\mathrm{a}}$

\begin{tabular}{|c|c|c|c|c|c|c|c|c|}
\hline Variables & Mean & Commit & Auto & Consid & Struct & Reward & Values & Phil \\
\hline Commitment & $\begin{array}{c}74.81 \\
(12.57)\end{array}$ & --- & & & & & & \\
\hline Autonomy & $\begin{array}{l}10.28 \\
(3.69)\end{array}$ & .26 & --- & & & & & \\
\hline Consideration & $\begin{array}{l}19.30 \\
(5.05)\end{array}$ & .59 & .41 & $--\cdot$ & & & & \\
\hline Structure & $\begin{array}{l}13.05 \\
(3.08)\end{array}$ & .05 & .08 & .12 & $-\cdots$ & & & \\
\hline Rewards & $\begin{array}{l}16.64 \\
(5.00)\end{array}$ & .50 & .35 & .61 & .06 & $\cdots$ & & \\
\hline $\begin{array}{l}\text { Value } \\
\text { Similarity }\end{array}$ & $\begin{array}{l}22.96 \\
(7.11)\end{array}$ & .34 & .29 & .47 & .12 & .48 & -.- & \\
\hline $\begin{array}{l}\text { Company } \\
\text { Philosophy }\end{array}$ & $\begin{array}{l}30.85 \\
(6.69)\end{array}$ & .63 & .26 & .62 & .03 & .51 & .40 & -- \\
\hline
\end{tabular}




\section{Moderator Regression}

Moderated regression analysis was used to examine the nature of the relationships among the four dimensions of climate, the two components of culture, and commitment. This analytic strategy has been discussed by Cohen and Cohen (1975), Zedeck (1971), and Arnold (1982). Moderated regression involves the entry of the independent variable (dimension of climate) in the first step, the entry of the moderator variable (component of culture) on the second step, and the entry of the interaction (climate $x$ culture) on the last step. The first two steps reflect a hierarchical regression model (Cohen and Cohen 1975). The interaction captures the moderating effect of culture on the

TABLE 3

MODERATED REGRESSION RESULTS OF VALUE SIMILARITY ON THE RELATIONSHIP BETWEEN DIMENSIONS OF CLIMATE AND ORGANIZATIONAL COMMITMENT

\begin{tabular}{|c|c|c|c|c|}
\hline \multirow{2}{*}{ MODERATOR } & \multicolumn{4}{|c|}{ ORGANIZATIONAL COMMITMENT } \\
\hline & $\mathrm{R}^{2}$ & $\begin{array}{c}\text { Change } \\
\mathrm{R}^{2}\end{array}$ & $\underset{\text { (partial) }}{\mathbf{F}}$ & $\begin{array}{c}\mathrm{F} \\
\text { (overall) }\end{array}$ \\
\hline \multicolumn{5}{|l|}{ MODELS OF CLIMATE } \\
\hline $\begin{array}{l}A U T \\
A U T+V S \\
A U T+V S+A U T V S\end{array}$ & $\begin{array}{l}.065 \\
.140 \\
.140\end{array}$ & $\begin{array}{l}.065 \\
.075 \\
.000\end{array}$ & $\begin{array}{c}13.80^{* * *} \\
.27\end{array}$ & $\begin{array}{r}11.17^{* *} \\
12.94^{* * *} \\
8.57^{* * *}\end{array}$ \\
\hline $\begin{array}{l}\text { CONS } \\
\text { CONS + VS } \\
\text { CONS + VS + CONSVS }\end{array}$ & $\begin{array}{l}.347 \\
.352 \\
.355\end{array}$ & $\begin{array}{l}.347 \\
.005 \\
.003\end{array}$ & $\begin{array}{r}1.22 \\
.79\end{array}$ & $\begin{array}{l}85.06^{* * *} \\
43.20^{* * *} \\
29.02^{*+*}\end{array}$ \\
\hline $\begin{array}{l}\text { STR } \\
\text { STR + VS } \\
\text { STR + VS + STRVS }\end{array}$ & $\begin{array}{l}.003 \\
.114 \\
.116\end{array}$ & $\begin{array}{l}.003 \\
.111 \\
.002\end{array}$ & $\begin{array}{c}19.83^{\circ .0} \\
.43\end{array}$ & $\begin{array}{r}.40 \\
10.14^{* * *} \\
6.88^{* * *}\end{array}$ \\
\hline $\begin{array}{l}\text { REWD } \\
\text { REWD + VS } \\
\text { REWD + VS + REWDVS }\end{array}$ & $\begin{array}{l}.248 \\
.261 \\
.272\end{array}$ & $\begin{array}{l}.248 \\
.013 \\
.011\end{array}$ & $\begin{array}{l}2.70^{+} \\
2.43\end{array}$ & $\begin{array}{l}52.86^{* * *} \\
28.06^{* * *} \\
19.68^{* * *}\end{array}$ \\
\hline $\begin{array}{l}\text { "AUT = autonomy; } \\
\text { CONS = consideration; } \\
\text { STR = structure; } \\
\text { REWD = reward; } \\
\text { VS = value similarity; } \\
\text { AUTVS = autonomy x valt } \\
\text { CONSVS = consideration } \\
\text { STRVS = structure } x \text { value } \\
\text { REWDVS = reward } x \text { valu }\end{array}$ & $\begin{array}{l}\text { arity ir } \\
\text { simila } \\
\text { ity int }\end{array}$ & $\begin{array}{l}\text { action; } \\
\text { interacti } \\
\text { tion; }\end{array}$ & $\begin{array}{l}+\mathrm{p}<.10 \\
{ }^{+} \mathrm{p}<.05 \\
+\mathrm{p}<.01 \\
+\mathrm{p}<.001\end{array}$ & \\
\hline
\end{tabular}


relationship between climate and commitment.

Regression analyses were run separately for each dimension of climate and component of culture. Running separate models for each dimension of climate is necessary given the literature in support of the multiple climates argument (Schneider and Reichers 1983; Schneider, Parkington, and Buxton 1980). This argument suggests that more than one climate exists in a firm and thus reward, consideration, structure, and autonomy dimensions of climate must be examined individually as independent variables. Preliminary factor analysis revealed value similarity and company philosophy to be two clearly distinct factors; hence these two components of culture were examined as separate moderators.

Table 3 provides the results of the moderated regression when the moderator is value similarity. As this table indicates, three of the four climate variables (autonomy, consideration, and rewards) provide significant explanatory power. Value similarity provides unique incremental variance in commitment beyond that provided for by autonomy, structure, and rewards in separate models. When consideration is the climate measure, value similarity does not provide significant additional variance explained.

These results indicate significant main effects for autonomy, rewards, and value similarity when entered in separate models to explain commitment. A model with consideration and value similarity as the independent variables only yields a main effect for consideration, whereas a model with structure and value similarity only yields a main effect for the value similarity measure. In sum, two of the four models yield significant main effects for both climate measures (i.e., autonomy and rewards) and value similarity.

Interestingly, no support was found for the moderating effects of the value similarity $X$ climate interaction. The moderating effects of value similarity were not significant for any of the models shown in Table 3 . This result suggests that the interaction term did not provide a significant change in $R^{2}$. The absence of an interaction effect suggests that while some dimensions of climate and value similarity have significant main effects on commitment, they do not interact to explain commitment. Value similarity does not moderate the relationship between the perceptions of the organization's climate and commitment; however, it does account for a significant portion of explanatory variance in commitment.

Table 4 summarizes the findings when company philosophy is the moderator variable. Company philosophy provided a significant main effect for all four of the models tested. In addition, all but one dimension of climate (i.e., 
structure) provided significant main effects. The analyses further revealed that company philosophy served as a moderator for two of the climatecommitment relationships. The interaction term provided a significant increment in the variance explained beyond that accounted for separately by climate and company philosophy when the consideration and reward dimensions of climate were the focus of the analysis. Thus support was found for the second hypothesis when company philosophy is the moderating variable.

\section{Subgroup Analysis}

To examine the form of the climate-commitment relationship at different intensities of company philosophy, we conducted a subgroup regression analysis for the relationships found to have significant interactions. Since only the

TABLE 4

MODERATED REGRESSION RESULTS OF COMPANY PHILOSOPHY ON THE RELATIONSHIP BETWEEN DIMENSIONS OF CLIMATE AND ORGANIZATIONAL COMMITMENT

\begin{tabular}{|c|c|c|c|c|}
\hline \multirow{2}{*}{$\begin{array}{l}\text { MODERATOR } \\
\text { Company Philosophy }\end{array}$} & \multicolumn{4}{|c|}{ ORGANIZATIONAL COMMITMENT } \\
\hline & $\mathbf{R}^{2}$ & $\underset{\mathbf{R}^{2}}{\text { Change }}$ & $\underset{\text { (partial) }}{\mathrm{F}}$ & $\underset{\text { (overall) }}{\mathbf{F}}$ \\
\hline \multicolumn{5}{|l|}{ MODELS OF CLIMATE } \\
\hline $\begin{array}{l}\text { AUT } \\
\text { AUT + PHIL } \\
\text { AUT + PHIL + AUTPHIL }\end{array}$ & $\begin{array}{l}.065 \\
.408 \\
.411\end{array}$ & $\begin{array}{l}.065 \\
.343 \\
.003\end{array}$ & $\begin{array}{l}92.31^{*} \\
.68\end{array}$ & $\begin{array}{l}11.17^{* *} \\
54.93^{* *} \\
36.77^{* *}\end{array}$ \\
\hline $\begin{array}{l}\text { CONS } \\
\text { CONS + PHIL } \\
\text { CONS + PHIL + CONSPHIL }\end{array}$ & $\begin{array}{l}.350 \\
.460 \\
.470\end{array}$ & $\begin{array}{l}.350 \\
.110 \\
.010\end{array}$ & $\begin{array}{l}33.32^{\cdots} \\
3.45^{+}\end{array}$ & $\begin{array}{l}85.06^{* *} \\
67.78^{* *} \\
47.03^{*}\end{array}$ \\
\hline $\begin{array}{l}\text { STR } \\
\text { STR + PHIL } \\
\text { STR + PHIL + STRPHIL }\end{array}$ & $\begin{array}{l}.003 \\
.401 \\
.406\end{array}$ & $\begin{array}{l}.003 \\
.398 \\
.005\end{array}$ & $\begin{array}{l}105.58^{* * *} \\
1.48\end{array}$ & $\begin{array}{l}.40 \\
53.12^{* *} \\
36.02^{* *}\end{array}$ \\
\hline $\begin{array}{l}\text { REWD } \\
\text { REWD + PHIL } \\
\text { REWD + PHIL + REWDPHIL }\end{array}$ & $\begin{array}{l}.248 \\
.443 \\
.465\end{array}$ & $\begin{array}{l}.248 \\
.195 \\
.022\end{array}$ & $\begin{array}{l}55.39^{* *} \\
6.75^{* *}\end{array}$ & $\begin{array}{l}52.12^{*+1} \\
63.11^{\cdots+} \\
45.68^{*+*}\end{array}$ \\
\hline $\begin{array}{l}\text { "AUT = autonomy; } \\
\text { CONS = consideration; } \\
\text { STR = structure; } \\
\text { REWD = reward; } \\
\text { PHIL = corporate philosophy; } \\
\text { AUTPHIL = autonomy } \times \text { philo } \\
\text { CONSPHIL = consideration } x \\
\text { STRPHIL = structure } \times \text { philos } \\
\text { REWDPHL = reward } \times \text { philos }\end{array}$ & $\begin{array}{l}\text { ophy } \\
\text { hilose } \\
\text { hy in } \\
\text { phy i }\end{array}$ & $\begin{array}{l}\text { raction; } \\
\text { interact } \\
\text { ction; } \\
\text { action }\end{array}$ & $\begin{aligned}+ & \mathrm{p}<.10 \\
* \mathrm{p} & <.05 \\
. * \mathrm{p} & <.01 \\
\cdots & \mathrm{p}<.001\end{aligned}$ & \\
\hline
\end{tabular}


company philosophy component of culture was found to have a significant interaction with climate, subgroups on this measure were formed by splitting with respondents according to their median scores. In one group were those who scored high on the company philosophy measure, indicating that they expressed high levels of understanding of the company vision. Those scoring low on the company philosophy measure were less knowledgeable about the organization's vision.

Commitment was regressed on the consideration and reward dimensions of climate in each of the two company philosophy subgroups. These two dimensions of climate were selected because their interaction terms in the moderator regression analyses were significant. Figures 1 and 2 illustrate the interaction effects of the strong and weak company philosophy subgroups on the relationship between climate and commitment.

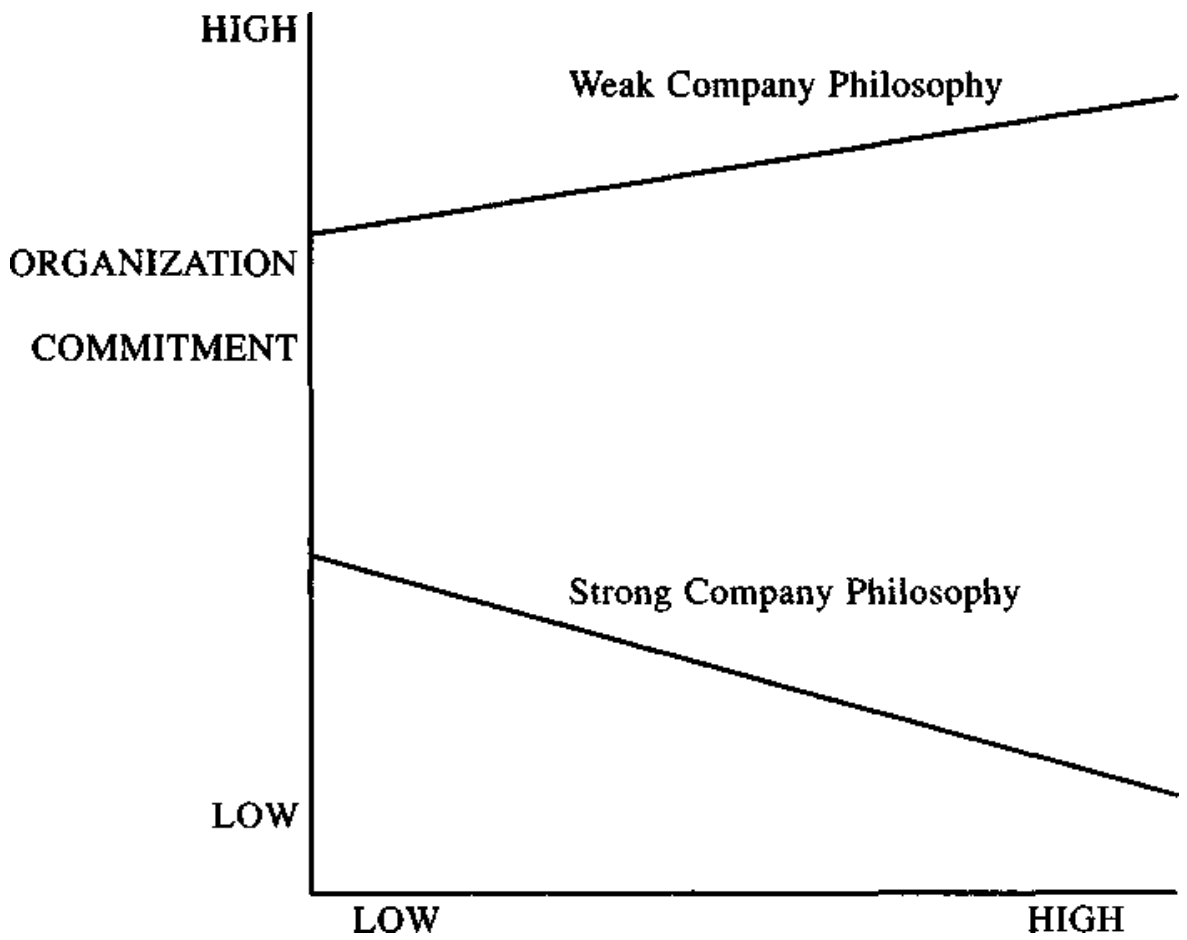

CONSIDERATION DIMENSION OF CLIMATE

Figure 1

SUBGROUP REGRESSION RESULTS FOR THE RELATIONSHIP 
As Figure 1 shows, the relationship between the climate for consideration and organization commitment differs for different levels of company philosophy. For those with a strong knowledge of the company philosophy, increases in the climate for consideration lead to decreases in commitment. When employees have a weak knowledge of the company philosophy, increases in the climate for consideration lead to only gradual increases in commitment.

For the reward dimension of climate (see Figure 2), the nature of the relationship between climate and commitment varies with the strength of the company philosophy. When employees have a weak knowledge of the company philosophy, increases in the climate for rewards only moderately lead to

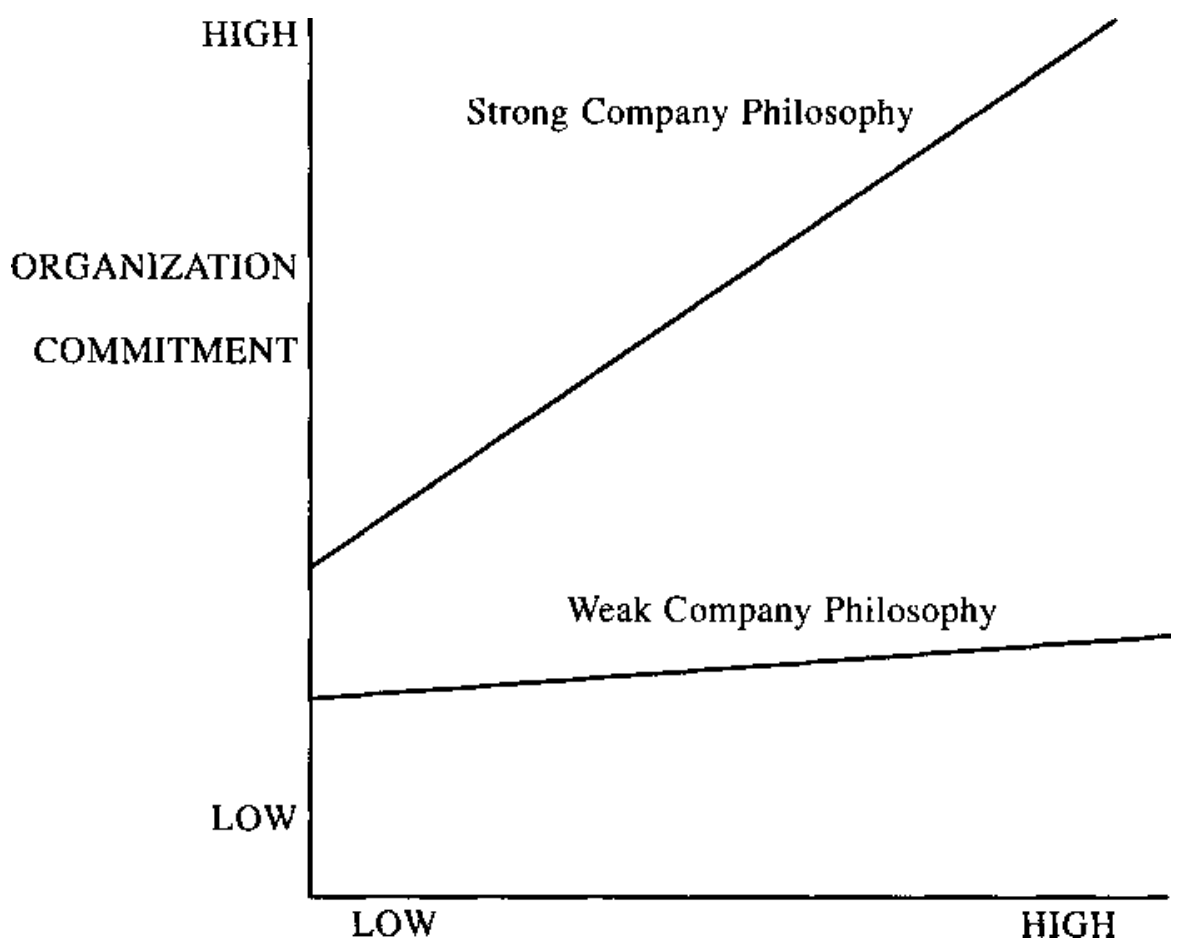

REWARD DIMENSION OF CLIMATE

Figure 2

SUBGROUP REGRESSION RESULTS FOR THE RELATIONSHIP BETWEEN THE REWARD DIMENSION OF CLIMATE AND COMMITMENT MODERATED BY COMPANY PHILOSOPHY 
increases in commitment. In contrast, when the knowledge of the company philosophy is strong, increases in the climate for rewards lead to substantial increases in organizational commitment.

\section{DISCUSSION}

Value similarity and company philosophy were found to be related to organizational commitment, as were all of the dimensions of perceived organizational climate, except structure. Given the low reliability of the structure measure, it is not surprising that this dimension of climate yielded insignificant findings. The results suggest that higher levels of value similarity and a stronger company philosophy are linked to higher levels of organizational commitment. In addition, an organizational climate that rewards effort, provides support and warmth, and permits autonomy is linked to higher levels of commitment.

The present study examined the potential moderating effects of value similarity and company philosophy on the relationship between climate and commitment. Interestingly, the results suggest that autonomy, rewards, consideration, and value similarity independently account for significant variance explained in commitment, but the degree of value similarity did not have significant interaction effects. This finding suggests that some dimensions of climate are invariant at different levels of value similarity. Hence, value similarity is an important factor in our understanding of commitment, but does not moderate the relationship between dimensions of perceived climate and organizational commitment. Main effects were also present for company philosophy, but in addition, this variable moderated the relationships between the climate for consideration and commitment.

Examination of the form of the interactions between climate and company philosophy revealed an interesting and unexpected finding. One would expect that the levels of commitment would increase as the climate for consideration increased in a situation of strong company philosophy. In this study commitment decreased in the strong company philosophy condition. One possible explanation for the decrease in commitment is that when the company philosophy is strong, high levels of consideration are unnecessary or indeed detrimental to building increased commitment, perhaps because the employees share or identify with the company philosophy. By sharing the same understandings of what the organization is attempting to accomplish, it is unnecessary to create a considerate organizational climate in order to elicit commitment.

In contrast, the relationship between the reward climate and commitment is positively affected by a strong company philosophy, while being only slightly affected by a weak company philosophy. This finding suggests that the reward climate-commitment relationship is contingent on the strength of the company philosophy. When a strong company philosophy is present, increasing the climate for rewards dramatically increases 
organizational commitment. When the company philosophy is not well known (weak), increases in the reward climate yield very small changes in organizational commitment.

Two important outcomes emerge from this study. First, both climate and culture were found to be associated with organizational commitment. Second, the relationships between the reward and consideration dimensions of climate and organizational commitment did appear to be affected by the strength of the company philosophy. These findings suggest that some components of the organizational climate are influenced by the nature of the company philosophy. In contrast, value similarity did not moderate the climate-commitment relationship but provided significant main effects for commitment. While sharing organizational loyalty, the degree of value sharing does not alter the relationship between the climate and commitment.

The findings of the present study highlight the relatively invariant nature of the relationship between climate and commitment when using value sharing as a moderator. In contrast, the strength of knowledge concerning the company philosophy does systematically cause the relationship between the climate and levels of commitment to change. Perhaps the most interesting implication of this latter finding is the possibility that a strong company philosophy enhances the positive commitment effects of a reward-based climate, while actually diminishing the positive commitment effects of a consideration-based climate. One might speculate that a strong company philosophy serves as a substitute for consideration while a weak philosophy makes it more essential that a considerate climate exist if high levels of commitment are desired. Future research would benefit by the exploration of additional cultural moderators and further inquiry into the role of cultural factors as substitutes and supplements for traditional antecedents of organizational commitment.

\section{References}

Angle, H. L., and J. L. Perry. 1981 "An Empirical Assessment of Organizational Commitment and Organizational Effectiveness." Administrative Science Quarterly 26: 1-13.

Arnold, H. J. 1982. "Moderator Variables: A Clarification of Conceptual, Analytical, and Psychometric Issues." Organizational Behavior and Human Performance 29: 143-74.

Bateman, T. S., and S. A. Strasser. 1984. "Longitudinal Analysis of the Antecedents of Organizational Commitment." Academy of Management Journal 27: 95-112.

Burke, W. 1985. "Organizational Culture and Organizational Climate Are Not the Same." Symposium presented at the 44th Annual Meeting of the Academy of Management, San Diego, CA, August. 
Campbell, J. P., M. D. Dunnette, E. E. Lawler, and K. E. Weick. 1980. Managerial Behavior, Performance, and Effectiveness. New York: McGraw- Hill.

Cohen, J., and P. Cohen. 1975. Applied Multiple Regression Correlation Analysis for the Behavioral Sciences. Hillsdale: Lawrence Earlbaum.

Deal, T. E., and A. A. Kennedy. 1982. Company Cultures: The Rites and Rituals of Company Life. Reading: Addison-Wesley.

Dennison, D. R. 1983. "Bringing Company Culture to the Bottom Line." Organizational Dynamics 5-22.

Dieterly, D. L., and B. Schneider. 1974. "The Effect of Organizational Environment on Perceived Power and Climate: A Laboratory Study." Organizational Behavior and Human Performance 11: 316-37.

Enz, C. A. 1988. "The Role of Organizational Value Congruity in Intraorganizational Power." Administrative Science Quarterly 33: 284-304.

In press. "The Relationship Between Organizational Value Sharing and Influence Over Strategic Decisions." International Journal of Value- Based Management.

Enz, C. A. and C. Schwenk. 1989. "Performance and the Sharing of Organizational Values." The National Academy of Management Meetings, Washington, D.C.

Field, R., and M. A. Abelson. 1982. "Climate: A Reconceptualization and Proposed Model." Human Relations 35: 181-201.

Hall, D. T., and B. Schneider. 1972. "Correlates or Organizational Identification as a Function of Career Pattern and Organizational Type." Administrative Science Quarterly 17: 340-50.

Koch, J. D., and R. M. Steers. 1978. "Job Attachment, Satisfaction and Turnover Among Public Sector Employees." Journal of Vocational Behavior 12: 119-28.

Lee, S. M. 1971. "An Empirical Analysis of Organizational Identification." Academy of Management Journal 14: 213-26.

Louis, M. R. 1983. "Organizations as Cultural-Bearing Milieux." Monographs in Organizational Symbolism. Ed. L. Pondy, P. Frost, G. Morgan, and T. Dandridge. Greenwich: JAI Press. 1: 39-65.

Morris, J. H., and J. D. Sherman. 1981. "Generalizability of an Organizational Commitment Model." Academy of Management Journal 22: 512-26.

Mowday, R. T., R. M. Steers, and L. Porter. 1979. "The Measurement of Organizational Commitment." Journal of Vocational Behavior 14: 224-47.

O'Reilly, C. A. 1983. "Corporations, Cults, and Organizational Culture: Lessons from Silicon Valley Firms." Paper presented at the 42nd Annual Meeting of 
the Academy of Management, Dallas, TX, August.

O’Toole, J. J. 1979. "Corporate and Managerial Cultures." Behavioral Problems in Organizations. Ed. G. Cooper. Englewood Cliffs: Prentice Hall. 7-28.

Ott, J. S. 1989. The Organizational Culture Perspective. Chicago: Dorsey Press.

Peters, T., and R. Waterman. 1983. In Search of Excellence: Lessons From American's Best-Run Companies. New York: Harper \& Row.

Pettigrew, A. M. 1979. On Studying Organizational Cultures." Administrative Science Quarterly 24.4: 570-81.

Porter, L. W., R. M. Steers, R. T. Mowday, and P. V. Boulian. 1974. “Organizational Commitment, Job Satisfaction, and Turnover Among Psychiatric Technicians." Journal of Applied Psychology 5: 603-09.

Posner, B. Z., J. M. Kouzes, and W. H. Schmidt. 1985. "Shared Values Make a Difference: An Empirical Test of Company Culture." Human Resource Management 24.3: 293-309.

Rousseau, D. M. 1989. "The Construction of Climate in Organizational Research." International Review of Industrial and Organizational Psychology. Ed. C. L. Cooper and I. Robertson. New York: Wiley. Vol. 3.

Safford, G. S. 1988. "Culture Traits, Strength, and Organizational Performance: Moving Beyond 'Strong' Culture." Academy of Management Review 13.4: $546-$ 58.

Sathe, V. 1983. "Implications of Company Culture: A Manager's Guide to Action." Organizational Dynamics Autumn: 5-23.

Schein, E. H. 1985. Organizational Culture and Leadership. San Francisco: Jossey-Bass.

Schneider, B. 1985. "Organizational Behavior." Annual Review of Psychology 36: 573-611.

Schneider, B., J. J. Parkington, and V. M. Buxton. 1980. "Employee and Customer Perceptions of Service in Banks." Administrative Science Quarterly 25: 252-67.

Schneider, B., and A. E. Reichers. 1983. "On the Etiology of Climates." Personnel Psychology 36: 19-39.

Steers, R. M. 1977. "Antecedents and Outcomes of Organizational Commitment." Administrative Science Quarterly 22: 46-56.

Trice, H. M., and J. M. Beyer. 1984. "Studying Organizational Cultures Through Rites and Ceremonials." Academy of Management Review 9: 65369.

Trice, H. M., J. M. Beyer, and D. Morand. 1985. “Climate and Culture: Mutually 
Exclusive Concepts and Data." Unpublished paper.

Welsch, H. P., and H. La Van. 1981. "Interrelationships Between Organizational Commitment and Job Characteristics, Job Satisfaction, Professional Behavior and Organizational Climate." Human Relations 34.12: 1079-89.

Wiener, Y. 1988. "Forms of Value Systems: A Focus on Organizational Effectiveness and Cultural Change and Maintenance." Academy of Management Review 13: 534-45.

Zedeck, S. 1971. "Problems With the Use of 'Moderator' Variables." Psychological Bulletin 76: 295-310. 